\title{
Cleaving of TOPAS and PMMA microstructured polymer optical fibers: Core-shift and statistical quality optimization
}

\author{
Stefani, Alessio; Nielsen, Kristian; Rasmussen, Henrik K.; Bang, Ole
}

Published in:

Optics Communications

Link to article, DOI:

10.1016/j.optcom.2011.12.033

Publication date:

2012

Document Version

Peer reviewed version

Link back to DTU Orbit

Citation (APA):

Stefani, A., Nielsen, K., Rasmussen, H. K., \& Bang, O. (2012). Cleaving of TOPAS and PMMA microstructured polymer optical fibers: Core-shift and statistical quality optimization. Optics Communications, 285(7), 1825-1833. https://doi.org/10.1016/j.optcom.2011.12.033

\section{General rights}

Copyright and moral rights for the publications made accessible in the public portal are retained by the authors and/or other copyright owners and it is a condition of accessing publications that users recognise and abide by the legal requirements associated with these rights.

- Users may download and print one copy of any publication from the public portal for the purpose of private study or research.

- You may not further distribute the material or use it for any profit-making activity or commercial gain

- You may freely distribute the URL identifying the publication in the public portal 


\title{
Cleaving of TOPAS and PMMA microstructured polymer optical fibers: core-shift and statistical quality optimization
}

\author{
A. Stefani ${ }^{\text {a, }}$, K. Nielsen ${ }^{a}$, H.K. Rasmussen ${ }^{b}$, and O. Bang ${ }^{a}$ \\ ${ }^{a}$ Technical University of Denmark, DTU Fotonik, Department of Photonics Engineering, DK-2800 Kgs. Lyngby, \\ Denmark \\ ${ }^{b}$ Technical University of Denmark, DTU Mechanical Engineering, Department of Mechanical Engineering, DK-2800 \\ Kgs. Lyngby, Denmark \\ *alste@fotonik.dtu.dk
}

\begin{abstract}
We fabricated an electronically controlled polymer optical fiber cleaver, which uses a razor blade guillotine and provides independent control of fiber temperature, blade temperature, and cleaving speed. To determine the optimum cleaving conditions of microstructured polymer optical fibers (mPOFs) with hexagonal hole structures we developed a program for cleaving quality optimization, which reads in a microscope image of the fiber end facet and determines the core-shift and the statistics of the hole diameter, hole-to-hole pitch, hole ellipticity, and direction of major ellipse axis. For 125 micron in diameter mPOFs of the standard polymer PMMA we found the optimum temperatures to be $77.5^{\circ} \mathrm{C}$ for both blade and fiber. For 280 micron in diameter mPOFs of the humidity insensitive polymer TOPAS ${ }^{\circledR}$ (grade 8007 ) the optimum temperature was 40 degrees for both blade and fiber. A 100 micron thick flat-edge blade was found to minimize the core shift by the cleaving to only $298 \mathrm{~nm}$ or $5 \%$ of the pitch for the PMMA mPOF at the optimal temperature.
\end{abstract}

Keywords: cleaving, microstructured polymer optical fibers, PMMA, TOPAS

References and links

1. M.A. van Eijkelenborg, M.C. J. Large, A. Argyros, J. Zagari, S. Manos, N.A. Issa, I. Bassett, S. Fleming, R.C. McPhedran, C.M. de Sterke, N.A.P. Nicorovici., "Microstructured polymer optical fibre", Opt. Express 9(7), 319-327 (2001).

2. M.A. van Eijkelenborg, A. Argyros, G. Barton, I.M. Bassett, M. Fellew, G. Henry, N.A. Issa, M.C.J. Large, S. Manos, W. Padden, L. Poladian, J. Zagari, "Recent progress in microstructured polymer optical fibre fabrication and characterisation", Opt. Fiber Technology 9(4), 199-209 (2003).

3. M.C.J. Large, A. Argyros, F. Cox, M.A. van Eijkelenborg, S. Ponrathnam, N.S.Pujari, I.M. Bassett, R. Lwin, G.W. Barton, "Microstructured polymer optical fibres: new opportunities and challenges", Molecular Crystals and Liquid Crystals 446, 219-231 (2006).

4. R. Lwin, G. Barton, L. Harvey, J. Harvey, D. Hirst, S. Manos, M.C.J. Large, L. Poladian, A. Bachmann, H. Poisel, K.-F. Klein, "Beyon the bandwidth-length product: Graded index microstructured polymer optical fiber", Appl. Phys. Lett. 91, 191119 (2007).

5. A. Argyros, M. Van Eijkelenborg, M.C.J. Large, I.M. Bassett, "Hollow-core microstructured polymer optical fiber", Opt. Lett. 31(2), 172-174 (2006).

6. M.C.J. Large, S. Ponrathnam, A. Argyros, N.S. Pujari, F. Cox, "Solution doping of microstructured polymer optical fibres", Opt. Express 12(9), 1966-1971 (2004).

7. E. Pone, C. Dubois, N. Guo, Y. Gao, A. Dupuis, F. Boismenu, S. Lacroix, M. Skorobogatiy, "Drawing of the hollow all-polymer Bragg fibers", Opt. Exp. 14, 5838 (2006)

8. A. Dupuis, N. Guo, Y. Gao, N. Godbout, S. Lacroix, C. Dubois, M. Skorobogatiy, "Prospective for biodegradable microstructured optical fibers", Opt. Lett. 32, 109 (2007).

9. S. Law, G. Barton, M. van Eijkelenborg, C. Yan, R. Lwin, J. Gan, "The effect of fabrication parameters on the cleaving of microstructured polymer optical fibers", Novel Optical Systems Design and Optimization IX, Proceedings of SPIE - The International Society for Optical Engineering, Vol. 6289 (2006).

10. G. Emiliyanov, J.B. Jensen, O. Bang, P.E. Hoiby, L.H. Pedersen, E.M. Kjær, L. Lindvold, "Localized biosensing with TOPAS $®$ microstructured polymer optical fiber”, Opt. Lett. 32, 460-462 (2007).

11. G. Emiliyanov, J.B. Jensen, O. Bang, P.E. Hoiby, L.H. Pedersen, E.M. Kjær, L. Lindvold, "Localized biosensing with TOPAS ${ }^{\circledR}$ microstructured polymer optical fiber: Erratum”, Opt. Lett. 32(9), 1059 (2007).

12. I.P. Johnson, W. Yuan, A. Stefani, K. Nielsen, H.K. Rasmussen, L. Khan, D.J. Webb, K. Kalli, O. Bang, Optical fibre Bragg grating recorded in TOPAS ${ }^{\circledR}$ cyclic olefin copolymer, Electron. Lett. 47(4), 271-272 (2011). 
13. W. Yuan, L. Khan, D.J. Webb, K. Kalli, H.K. Rasmussen, A. Stefani, O. Bang, "Humidity insensitive TOPAS® polymer fiber Bragg grating sensor" (submitted).

14. K. Nielsen, H.K. Rasmussen, A.J.L. Adam, P.C.M. Planken, O. Bang, P.U. Jepsen, "Bendable, low-loss TOPAS $®$ fibers for the terahertz frequency range", Optics Express 17, 8592-8601 (2009).

15. J.B. Jensen, P.E. Hoiby, G. Emiliyanov, O. Bang, L.H. Pedersen, A. Bjarklev, "Selective detection of antibodies in microstructured polymer optical fibers," Opt. Express 13, 5883-5889 (2005)

16. F. M. Cox, A. Argyros, M. C. J. Large, "Liquid-filled hollow core microstructured polymer optical fiber," Opt. Express 14(9), 4135-4140 (2006)

17. F.M. Cox, A. Argyros, M.C.J. Large, S. Kalluri, "Surface enhanced Raman scattering in a hollow core microstructured optical fiber," Opt. Express 15, 13675-13681 (2007)

18. H. Dobb, D.J Webb, K. Kalli, A. Argyros, M.C.J. Large, M.A. van Eijkelenborg, ”Continuous wave ultraviolet light-induced fiber Bragg gratings in few- and single-mode microstructured polymer optical fibers", Opt. Lett. 30(24), 3296-3298 (2005).

19. K.E. Carroll, C. Zhang, D.J. Webb, K. Kalli, A. Argyros, M.C.L. Large, ”Thermal response of Bragg gratings in PMMA microstructured optical fibers", Opt. Express 15(14), 8844-8850 (2007)

20. D.J. Webb and K. Kalli: 'Polymer fiber Bragg gratings', in Fiber Bragg Grating Sensors: Recent Advancements, Industrial Applications and Market Exploitation, A. Cusano, A. Cutolo, and J. Albert (Eds.), chapter 15, pp. 1-20. (Bentham Science Publishers Ltd. 2009)

21. I.P. Johnson, K. Kalli, D.J. Webb, " $827 \mathrm{~nm}$ Bragg grating sensor in multimode microstructured polymer optical fiber", Electron. Lett. 46(17), 1217-1218 (2010)

22. W. Yuan, A. Stefani, M. Bache, T. Jacobsen, B. Rose, N. Herholdt-Rasmussen, F.K. Nielsen, S. Andresen, O.B. Sørensen, K.S. Hansen, O. Bang, "Improved thermal and strain performance of annealed polymer optical fiber Bragg gratings", Opt. Commun. 284, 176-182 (2011).

23. A. Stefani, W. Yuan, C. Markos, O. Bang, "Narrow bandwidth 850nm Fiber Bragg gratings in few-mode polymer optical fibers", IEEE Phot. Techn. Lett. 23(10), 660-662 (2011).

24. M. A. van Eijkelenborg, W. Padden, J. A. Besley, "Mechanically induced long-period gratings in microstructured polymer fibre", Opt. Commun. 236, 75-78 (2004).

25. M.P. Hiscocks, M.A. van Eijkelenborg, A. Argyros, M.C.J. Large, ”Stable imprinting of long-period gratings in microstructured polymer optical fibre", Opt. Express 14(11), 4644-4649 (2006).

26. M.C.J. Large, L. Poladian, G. Barton, M.A. van Eijkelenborg, "Microstructured polymer optical fibres," Springer, (2008)

27. M.C.J. Large, D. Blacket, C.-A. Bunge, "Microstructured Polymer Optical Fibers Compared to Conventional POF: Novel Properties and Applications", IEEE Sensors J. 10(7), 1213-1217 (2010).

28. L. Rindorf, J.B Jensen, M. Dufva, P.E. Hoiby, L.H. Pedersen, O. Bang, "Photonic crystal fiber long-period gratings for biochemical sensing", Opt. Express 14(18), 8224-8231 (2006).

29. L. Rindorf, O. Bang, "Sensitivity of photonic crystal fiber grating sensors: biosensing, refractive index, strain, and temperature sensing", J. Opt. Soc. Am. B 25(3), 310-324 (2008).

30. S.H. Law, M.A. van Eijkelenborg, G.W. Barton, C. Yan, R. Lwin, J. Gan, "Cleaved end-face quality of microstructured polymer optical fibres", Opt. Commun. 265(2), 513-520 (2006-Sep).

31. J. Canning, E. Buckley, N. Groothoff, B. Luther-Davies, J. Zagari, "UV laser cleaving of air-polymer structured fibre", Opt. Commun. 202, 139-143 (2002).

32. S. Atakaramians, K. Cook, H. Ebendorff-Heidepriem, S. Afshar V., J. Canning, D. Abbott, T.M. Monro, "Cleaving of extremely porous polymer fibers", IEEE Photon.J. 1(6), 286-292 (2009).

33. O. Abdi, K.C. Wong, T. Hassan, K.J. Peters, M.J. Kowalsky, "Cleaving of solid single mode polymer optical fiber for strain sensor applications", Opt. Commun. 282, 856-861 (2009).

34. S.H. Law, J.D. Harvey, R.J. Kruhlak, M. Song, E. Wu, G.W. Barton, M.A. van Eijkelenborg, M.C.J. Large, "Cleaving of microstructured polymer optical fibres", Opt. Commun. 258(2), 193-202 (2006-Feb).

35. N.A. Mortensen, "Semianalytical approach to short-wavelength dispersion and modal properties of photonic crystal fibers," Opt. Lett. 30, 1455-1457 (2005)

36. M. Koshiba and K. Saitoh, Applicability of classical optical fiber theories to holey fibers, Opt. Lett. 29, 1739-1741 (2004).

\section{Introduction}

The first microstructured Polymer Optical Fiber (mPOF) was fabricated in 2001 by van Eijkelenborg et al. at the Optical Fibre Technology Center (OFTC) in Sydney, Australia [1]. Since then mPOFs with a large variety of hole structures and thus specific optical properties, have been fabricated at the OFTC, including endlessly single-mode mPOFs [2-3], multi-mode graded-index mPOFs (GImPOFs) [2,4], hollow-core photonic bandgap guiding mPOFs [2-3,5], highly birefringent $\mathrm{mPOFs}$ [2], twin-core $\mathrm{mPOFs}$, [2], rectangular core mPOFs [4], solution- 
doped mPOFs [3,6]. All these mPOFs have been made of conventional PMMA, which is commercially available in optical-grade quality granulates and low industry-grade solid rods.

Multi-material mPOFs with layers of PMMA and polystyrene or polycarbonate, have been used for making bandgap air-guiding mPOFs in the form of hollow polymer Bragg Fibers [7]. Other materials, such as cellulose butyrate, has been used to fabricate multi-functional biodegradable mPOFs [8].

Recently TOPAS ${ }^{\circledR}$ Cyclic Olefin Copolymer (COC) is also increasingly being used [10-14] due to its unique properties for localized biosensing [10-11], humidity insensitive sensing [1213], and low-loss terahertz (THz) guidance [14]. Unfortunately, like optical-grade PMMA, TOPAS ${ }^{\circledR}$ COC only comes in granulate, which has to be processed. Nevertheless, TOPAS ${ }^{\circledR}$ and PMMA are together now the primary materials for mPOF fabrication.

Applications of mPOFs were initially hoped to be wide-ranging due to a number of advantageous material properties of polymer over silica in biosensing and strain sensing, the shear number of polymers to choose from, and the fact that polymers are drawn at low temperature, typically below $250^{\circ} \mathrm{C}$, making it possible to dope polymer fibers without destroying the dopant [6]. However, the high loss of PMMA (and TOPAS®) outside the visible wavelength regime and issues with splicing and cleaving, have severely hindered their applications. At present the main applications of mPOFs are within biosensing [10-11,15-17] and Fiber Bragg Grating (FBG) based straing sensing [12-13,18-23], even though early work has been done on Long Period Gratings (LPGs) in mPOFs also [24-25]. Polymers, such as PMMA and TOPAS $\AA$, are intrinsically photosensitive and thus mPOFs require no doping before an FBG can be UV-written into them, typically around $325 \mathrm{~nm}[12,18]$. In contrast, silica fibers typically require Ge-doping and hydrogen loading, before an FBG can be UV-written into them. For an excellent review of polymer fiber FBGs we refer to [20] and for an excellent overview on the mPOF technology we refer to [26-27].

The advantage of mPOFs in biosensing depends on the material. PMMA is for example highly biocompatible and thus biomolecules may be immobilized directly onto PMMA [19], in contrast to silica, which requires definition of several intermediate layers [28-29]. TOPAS ${ }^{\circledR}$ does not allow direct binding of biomolecules to it, but it enables one to use special UVactivated linker molecules to define localized biosensing capture layers in well-defined sections along the fiber [10-11]. Common to all polymers is that they remain flexible and do not produce shards when damaged, which makes them suitable for also in vivo applications.

Within strain sensing polymer fibers have a clear advantage over silica fibers because of their low Young's modulus and their ability to be stretched much more than silica without breaking [20,27-28]. PMMA mPOFs have for example a Young's modulus of 2-3 GPa, depending on the drawing conditions [30,9], in contrast to the about $72 \mathrm{GPa}$ of silica [26]. This means that much higher sensitivities can be achieved with mPOFs, if one can live with their lower operating temperature and higher loss [20]. Exactly due to the high loss of PMMA around 1550nm there has been a strong push towards writing FBGs for operation around 850nm [21,23], where CMOS components are available.

One of the major issues with mPOFs is their handling, such as cleaving and connectorization to silica fibers and other polymer fibers. Today, gluing is typically used to connect polymer fibers to a low-loss silica fiber in sensor applications, but care has to be taken when using mPOFs, in order to avoid too much glue going into the holes. 
Canning et al were the first to report on mPOF cleaving in 2002, where they used a $193 \mathrm{~nm} \mathrm{ArF}$ laser to cleave $200 \mu \mathrm{m}$ in diameter PMMA mPOFs, which had multiple cores distributed in a random air-polymer structure with thin bridges, surrounded by a thick solid region [31]. They found that ideally the rep. rate should be below $2 \mathrm{~Hz}$ to avoid damaging the fiber end-facet due to thermal build-up because of too long exposure to UV light. However, the cleaving time scales with the rep. rate and it was found that $4 \mathrm{~Hz}$ and an intensity of $1.6 \mathrm{~J} / \mathrm{cm}^{2}$ gave satisfactory cleaves in a reasonable time [31]. UV laser cleaving was again used several years later to cleave 400-500 $\mu \mathrm{m}$ in diameter highly porous PMMA mPOFs with high air-fill fraction and no outer solid region [32]. This study confirmed that UV laser cleaving gave clean endfacets and it showed that rotating the mPOFs by $3.6 \%$ during the cleaving process significantly improved the end-facet [32]. In this later study a $20 \mathrm{~Hz}$ rep. rate was used to shorten the cleaving time to about $270 \mathrm{~s}$, but as expected this high rep. rate lead to thermal build-up and degrading of the fiber end-facet [32].

In view of the results of [31-32] it appears that UV laser cleaving consistently gives good cleaves of PMMA mPOFs with even the most complicated hole structures. Focussed Ion Beam (FIB) milling can also be used to cleave PMMA mPOFs [32] and solid single-mode PMMA fibers [33] and provides even better end-facets. However, FIB milling is very expensive and time-consuming, with reported cleaving times of 17.5 hours [32].

Clearly price, portability, and cleaving time speak against UV laser cleaving and FIB milling, as was realized early on by Law et al, who instead developed the hot razor-blade/hot-fiber cleaving technique in a series of papers in 2006 [34,30,9]. In all these investigations the studied fiber was a PMMA GImPOF, typically with a diameter of around $400 \mu \mathrm{m}$ and a thick solid layer around the hole structure. The GImPOF has a range of hole sizes, which makes it ideal for the testing of cleaves.

In the first work of Law et al they found that the PMMA used in their GImPOF, had a brittle-toductile phase-transition close to $60^{\circ} \mathrm{C}$, which prevented good cleaves to be obtained above $60^{\circ} \mathrm{C}$ [34]. The brittleness of PMMA is known to depend strongly on its viscosity molecular mass $\left(M_{v}\right)$ with brittle behaviour occurring for $M_{v}<10^{4}$ and ductile behaviour for $M_{v}>10^{5}$, where the particular grade of PMMA used by Law et al had $\mathrm{M}_{\mathrm{v}}=7.2 \times 10^{4}$ [34]. The cleaving dynamics of PMMA is quite different in the brittle and ductile regions, with crack front propagation providing the cleaving in the brittle region and interfacial shearing by the blade itself providing the cleaving in the ductile region. Given that the mPOF hole structure forms a crack-stopping structure, it is not surprising that good cleaving could not be obtained above $60^{\circ} \mathrm{C}$.

Law et al first used a very simple hand-operated cleaver to cleave $580 \mu \mathrm{m}$ in diameter GImPOFs and found that above $60^{\circ} \mathrm{C}$ acceptable cleaves could be obtained with the best and most consistent results being for a fiber temperature of $85-95^{\circ} \mathrm{C}$ and a blade temperature of 50$80{ }^{\circ} \mathrm{C}$ [34]. Another cleaver was then built, which had independent control of the cleaving speed, the position of the blade, and the fiber and blade temperature. A subsequent study of a different $400 \mu \mathrm{m}$ in diameter GImPOFs (drawn at $220^{\circ} \mathrm{C}$ and $45 \mathrm{~g}$ tension) with a blade temperature of $60^{\circ} \mathrm{C}$ showed that the optimum fiber temperature had now increased to $70-80^{\circ} \mathrm{C}$ [34]. It was also found that an equilibration time of at least $40 \mathrm{~s}$ should be used between placing the fiber on the plate and cleaving it, with $60 \mathrm{~s}$ being used in the study [34]. The condition of the blade was found to be extremely important, with the optimum being to move the blade between each cut to use a clean pristine section for each cleave [34]. Finally the best cleaving speed was found to be below $0.5 \mathrm{~mm} / \mathrm{s}$, with the necessary speed increasing with temperature due to the softening of the fiber [34]. 
Further studies of identical PMMA GImPOFs showed in more detail the nature of the damage done by the cleaving and considered the correlation between the drawing conditions, the mechanical properties, and the optimum cleaving temperature [9,30]. Measurements on solid fibers of the same PMMA showed that the room temperature Young's modulus increased with increasing draw tension (decreasing temperature) and that the loss modulus had peaks at two characteristic temperatures, which both increased with increasing tension (decreasing temperature) [9,30]. The medium tension GImPOF was shown to have an optimum cleaving temperature close to the first peak in the loss modulus and it was conjectured that this correlation was in fact a general phenomenon $[9,30]$.

The hot-blade/fiber cleaving technique was also used for the cleaving of $110 \mu \mathrm{m}$ in diameter commercial single-mode solid step-index polymer fibers of PMMA with a slight doping of polystyrene in the core. From visual inspection of the roughness of 1275 cleaves it was found that in addition to the optimum about $80^{\circ} \mathrm{C}$ of both blade and fiber found by Law et al, a region of even better cleaves existed for fiber temperatures decreased to $30-40^{\circ} \mathrm{C}$ [33]. Whether this different optimum region is due to the fiber being doped with polystyrene, due to the fiber being made from a different PMMA or drawn at different conditions, or due to the fiber being allsolid, thereby only allowing end-facet roughness as a measure of the quality of a cleave, is uncertain.

Not all mPOF hole structures allow cleaving with the hot-blade/fiber technique. It has for example been reported that highly porous mPOFs with a high air-fill fraction and almost no solid material around the microstructure, cannot be cleaved satisfactorily with the hotblade/fiber technique [32]. These exotic fibers are, however, only of interest for THz guiding and not for fiber-optical sensing or optical transmission fibers. Other failed cleaving attempts of these highly porous $\mathrm{THz}$ fibers include using a semiconductor dicing saw [32].

The conclusion to make from the studies of PMMA mPOF cleaving with the hot-blade/fiber technique is that the optimum cleaving parameters depend significantly on the material properties of the drawn fiber, and thus also on the specific drawing conditions and the final hole structure. In PMMA mPOFs the optimum cleaving temperature was thus just above the brittleto-ductile phase transition. However, what are the optimum cleaving parameters of the emerging TOPAS $\AA$ mPOFs for example and can one further optimize the blade?

Only one study has so far been published on the cleaving of TOPAS ${ }^{\circledR}$ mPOFs, which was on the highly porous $\mathrm{mPOFs}$ for $\mathrm{THz}$ guiding [32]. The authors find that neither the hot-blade/fiber technique, nor FIB milling or the semiconductor dicing saw, allows good cleaving of 400-500 $\mu \mathrm{m}$ in diameter highly porous TOPAS ${ }^{\circledR}$ mPOFs [32]. They further argue that this is due to the low glass transition temperature $\left(\mathrm{T}_{\mathrm{g}}\right)$ of TOPAS $\AA$. We would like to note that the TOPAS ${ }^{\circledR}$ used in [32] is in fact grade 8007 with $\mathrm{T}_{\mathrm{g}}=80^{\circ} \mathrm{C}$, whereas other grades have glass transition temperatures higher than that of standard PMMA, such as TOPAS® grade 6017 with $\mathrm{T}_{\mathrm{g}}$ $=180^{\circ} \mathrm{C}$.

Here we present a thorough study of the cleaving of TOPAS® $\mathrm{mPOFs}$ with a triangular hole structure surrounded by a thick solid region. Such mPOFs can easily be made single-mode and even endlessly single-mode, which is why they have the best prospects for application in, e.g., fiber-optical sensing. The cleaving of such TOPAS ${ }^{\circledR} \mathrm{mPOFs}$ has not been considered before. We further study the cleaving of in-house fabricated mPOFs made of industry-grade PMMA, in particular considering how the blade can be improved. 


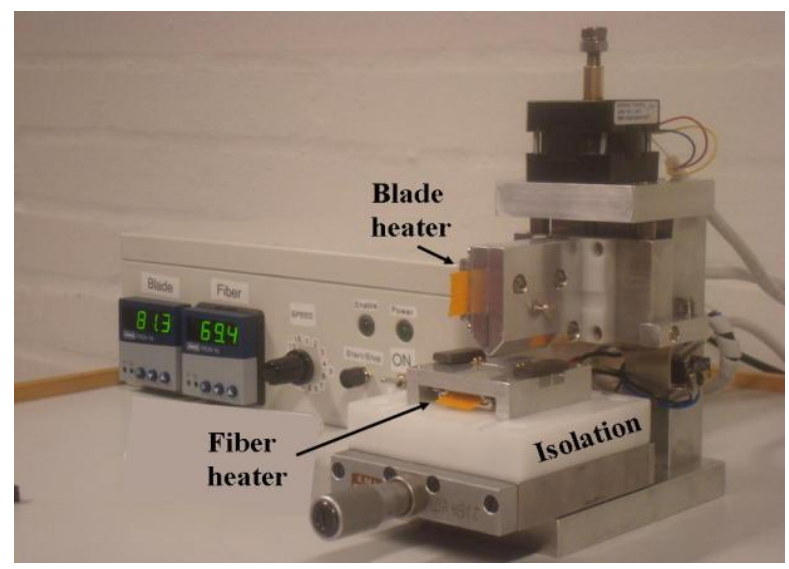

Fig. 1. Polymer fiber cleaver with independent electronic control of cleaving speed and temperature of blade and fiber

All studies of mPOF cleaving have so far relied on visual inspection. In order to have a repeatable process and minimizing the impact of the human eye, we developed a program for cleaving quality optimization, which reads in a microscope image of the fiber end facet and determines the statistics of the hole diameter, hole-to-hole pitch, hole ellipticity, and direction of major ellipse axis. The program also calculates the core-shift relative to the fiber center imposed by the cleaving, which is an important parameter for minimizing the coupling and splicing/gluing loss.

For repeatable cleaving we fabricated the electronically controlled cleaver shown in Fig. 1, which provides independent control of fiber temperature, blade temperature, and cleaving speed, just as the cleaver originally used by Law et al. [9,30,34].

Investigating several different blades of different thicknesses and shapes, we find the optimum blade to be a custom-made flat-edge blade with a thickness of $100 \mu \mathrm{m}$, which was the smallest thickness we had available.

For $125 \mu \mathrm{m}$ in diameter mPOFs of the standard polymer PMMA our results show that the optimum cleaving temperature is $77.5^{\circ} \mathrm{C}$ for both blade and fiber, thereby confirming that the temperatures found by Law et al. also hold for mPOFs made of industry-grade PMMA with the standard telecom diameter $125 \mu \mathrm{m}$. With the $100 \mu \mathrm{m}$ thick flat-edge blade the core-shift due to the cleaving had also its minimum at the optimum temperature, which was only $298 \mathrm{~nm}$, or $5 \%$ of the pitch.

For $280 \mu \mathrm{m}$ in diameter TOPAS® mPOFs (grade 8007) we found the optimum cleaving temperatures to be $40^{\circ} \mathrm{C}$ for both blade and fiber.

\section{2. mPOFs under investigation}

In our investigation we use the two mPOFs with hexagonal hole structures shown in Fig. 2: a PMMA 3-ring fiber and a TOPAS $® 2$-ring fiber. The PMMA fiber has been drawn in a twostep process from a $\mathrm{D}=6 \mathrm{~cm}$ in diameter preform, with 3 rings of holes with a hole-to-hole spacing, or pitch, of $\Lambda=6 \mathrm{~mm}$ and a hole diameter of $\mathrm{d}=3 \mathrm{~mm}$ drilled into it. The preform was drawn to a $5 \mathrm{~mm}$ in diameter cane. The cane was then sleeved with two PMMA tubes, achieving a secondary preform with a $2 \mathrm{~cm}$ outer diameter. The secondary preform was drawn 


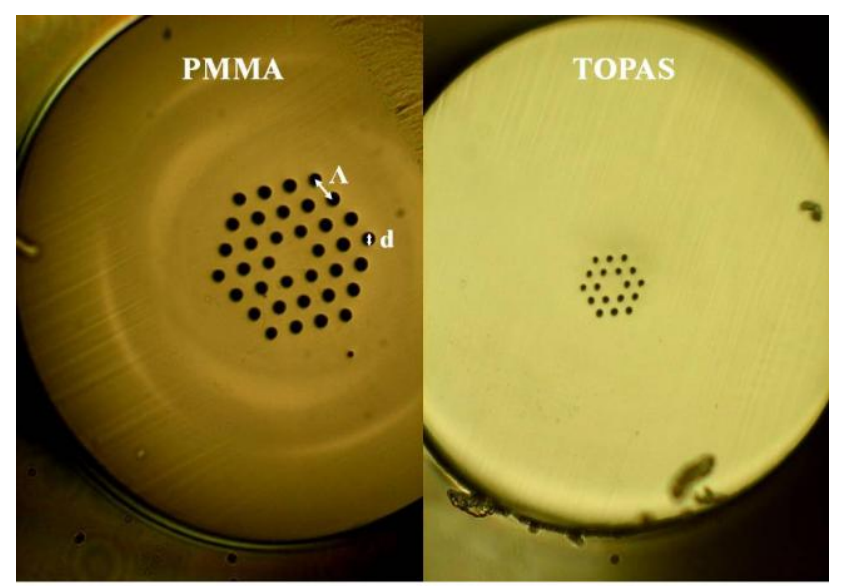

Fig. 2: Fibers under investigation: (left) PMMA $125 \mu \mathrm{m} \mathrm{mPOF}$ with 3 rings of holes with average pitch $\Lambda=5.92 \mu \mathrm{m}$ and average hole diameter $\mathrm{d}=2.76 \mu \mathrm{m}$; (right) TOPAS ${ }^{2} 280 \mu \mathrm{m}$ mPOF with 2 rings of holes with average pitch $\Lambda=8.4$ $\mu \mathrm{m}$ and average hole diameter $\mathrm{d}=2.9 \mu \mathrm{m}$ (right).

to a $125 \mu \mathrm{m}$ fiber (standard telecom diameter) with average hole diameter $\mathrm{d}=2.76 \mu \mathrm{m}$ and average pitch $\Lambda=5.92 \mu \mathrm{m}$ (see Fig. 5).

The fiber has been drawn at $30 \mathrm{~m} /$ minute with a set-temperature of $290^{\circ} \mathrm{C}$ and a tension of about $24 \mathrm{~g}$. According to the definition of low (5-8 g), medium (65 g), and high tension (130$150 \mathrm{~g}$ ) used in [9] this places our fiber in the mid-low regime and thus it should have a lower Young's modulus and require a higher cleaving speed and lower cleaving temperature than the $0.5 \mathrm{~mm} / \mathrm{s}$ and $80^{\circ} \mathrm{C}$ found for the medium tension GImPOF used in $[9,30,34]$.

The TOPAS ${ }^{\circledR} \mathrm{mPOF}$ has been drawn with the same procedure, but starting from a 2 ring preform $(\mathrm{D}=6 \mathrm{~cm}, \mathrm{~d} / \Lambda=3 / 6 \mathrm{~mm})$ of grade 8007 TOPAS ${ }^{\circledR}$ from and using a $3 \mathrm{~cm}$ secondary preform. The secondary preform was drawn to a $280 \mu \mathrm{m}$ fiber with $8.4 \mu \mathrm{m}$ average pitch and $2.9 \mu \mathrm{m}$ average hole diameter.

The TOPAS ${ }^{\circledR}$ mPOF has a hole diameter to pitch ratio of $d / \Lambda \approx 0.35$, which is well below the threshold of 0.42 that ensures endlessly single-mode operation of microstructued optical fibers of arbitrary base material [35]. The PMMA mPOF has a hole diameter to pitch ratio of $\mathrm{d} / \Lambda \approx$ 0.47 , which is just above the cut-off and thus it becomes multi-moded below a short wavelengths cut-off, which for $\mathrm{d} / \Lambda \approx 0.47$ is approximately $\lambda_{\text {cut-off }} \approx 0.2 \Lambda=1180 \mathrm{~nm}$ [36].

\section{Cleaving parameters}

All cleaves presented here have been made with a blade speed of $5.6 \mathrm{~mm} / \mathrm{s}$ and with an equilibrium time (time allowed to the fiber to reach thermal equilibrium) of about $20 \mathrm{~s}$ before cleaving the fiber.

The blade speed is over 10 times higher than the maximum of $0.5 \mathrm{~mm} / \mathrm{s}$ used for $400 \mu \mathrm{m}$ GImPOFs in $[9,30,34]$, reflecting the comparably low tension and high temperature used in our drawing, as discussed in Section 2. At low speeds the $5 \mu \mathrm{m}$ step length of our motor produces steps on the end-facet of the fiber, while this is not a problem at $5.6 \mathrm{~mm} / \mathrm{s}$. We note that in fact Law et al. also observed that a high speed was good when cutting at temperatures of $70^{\circ} \mathrm{C}$ or more [34]. 


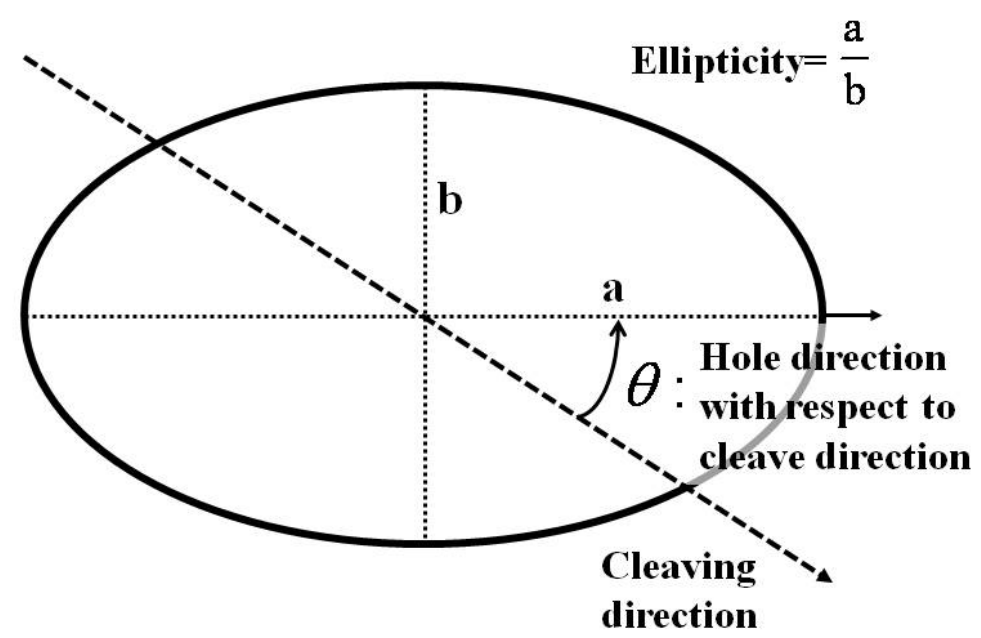

Fig. 3: Definition of elliptical fit: $a$ is the major axis, $b$ the minor axis, the dashed line represents the cleaving direction, and $\theta$ is the angle between the main axis (hole direction) and the cleaving direction.

The equilibrium time is 3 times less than the $60 \mathrm{~s}$ used in [30,34], which is mainly because our fibers are about 3 times thinner with less holes and thus reach thermal equilibrium faster.

With a fixed cleaving speed and equilibrium time we focus on determining the optimum temperature of fiber and blade for cleaving TOPAS ${ }^{\circledR}$ and PMMA mPOFs. Furthermore we investigate the influence of blade thickness.

In order to judge the quality of a cleave a code for analyzing the end-facet images of the cleaved fibers has been implemented in Matlab, which analyzes the outer fiber shape and the statistics of the hole structure. The program fits the contours of all the holes in the image with ellipses using the least squares approximation. From the fit we obtain the desired parameters of each ellipse: the length of the major and minor axes ( $\mathrm{a}$ and $\mathrm{b}$ in Fig. 3), the position of the center and the main axis direction with respect to a given direction, which we choose as the cleaving direction ( $\theta$ in Fig. 3). From now on the main axis direction is also denoted the hole direction.

We define the ellipticity as the ratio between the major and minor axis, a/b. A circular hole will have an ellipticity of 1 , whereas an ellipticity larger than 1 implies a deformed hole. The definition of the different parameters is shown in Fig. 3. The hole diameter is calculated as the arithmetic mean of the ellipse axes $(a+b) / 2$. The average hole diameter is then calculated as the arithmetic mean of all the hole diameters. The pitch is calculated as the distance between the centers of two adjacent holes. The fiber average pitch is then calculated as the arithmetical average between all the pitches.

The same elliptical fit is also done for the outer circumference of the fiber with the fiber diameter being calculated in the same way as the arithmetic mean of the ellipse axes. With this data we will also be able to calculate the shift of the microstructure (or core shift) because of the cleaving.

We finally note that the use of the numerical code for cleaving inspection is limited to a parameter regime in which the hole structure is intact after cleaving (no broken bridges), so that it can be analyzed. 


\section{Cleaving analysis - good cleave}
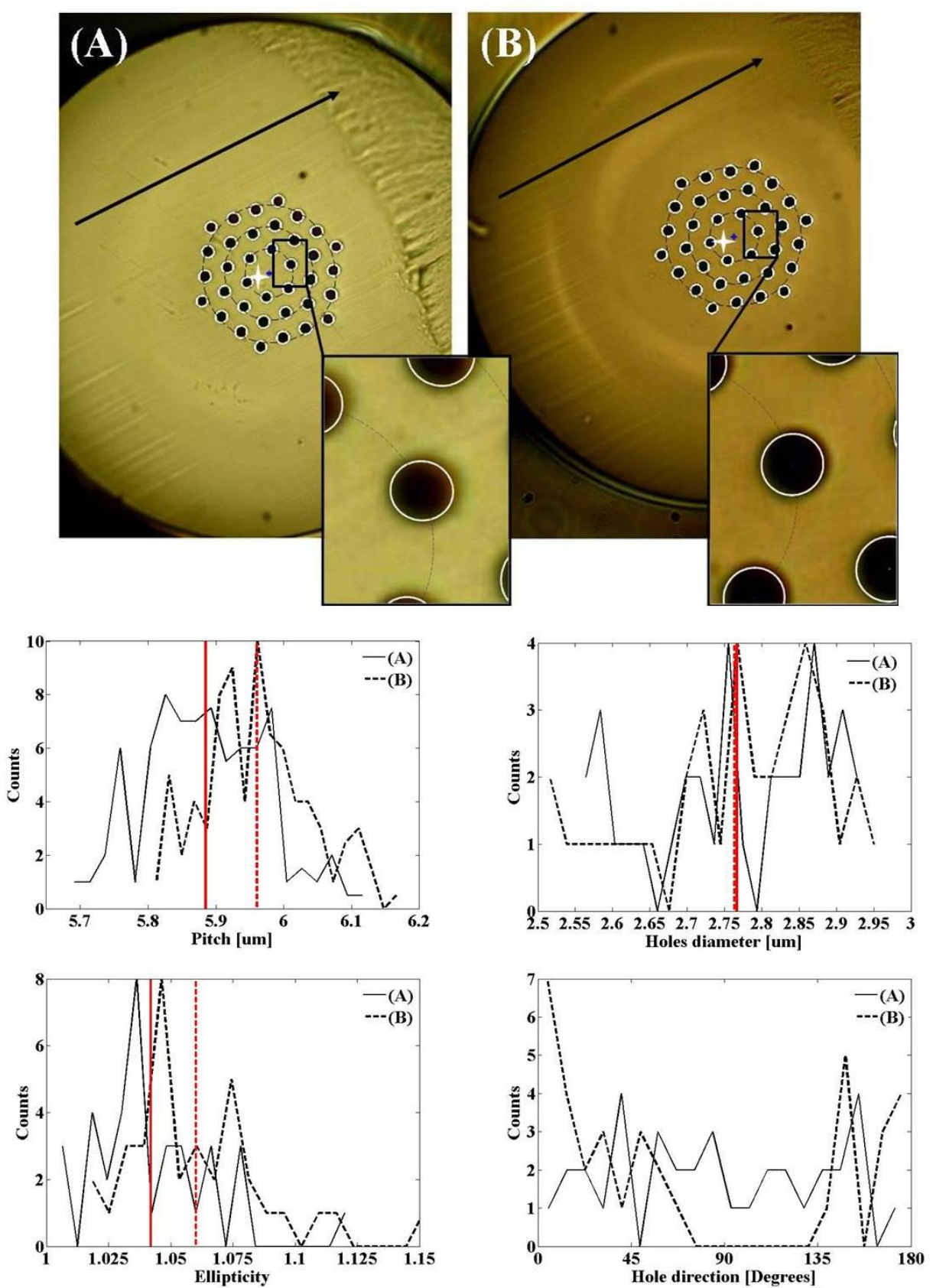

Fig. 4: Two cleaves of the PMMA mPOF made with the same settings $\left(77.5^{\circ} \mathrm{C}\right.$ for both blade and base, $130 \mu \mathrm{m}$ thick wedge-shaped blade) but with a different direction (black arrow) with respect to the hole structure. Cleave A (left) and $\mathrm{B}$ (right) are represented by solid and dashed lines, respectively. The $\mathrm{x}$-axis is divided into bins and the $\mathrm{y}$-axis shows the number of counts with a given parameter value in the bin. The curves are then the center of the bins connected with a line. In the pitch, hole diameter and ellipticity graphs the vertical lines represent average values. The white star on the images marks the center of the fiber. 

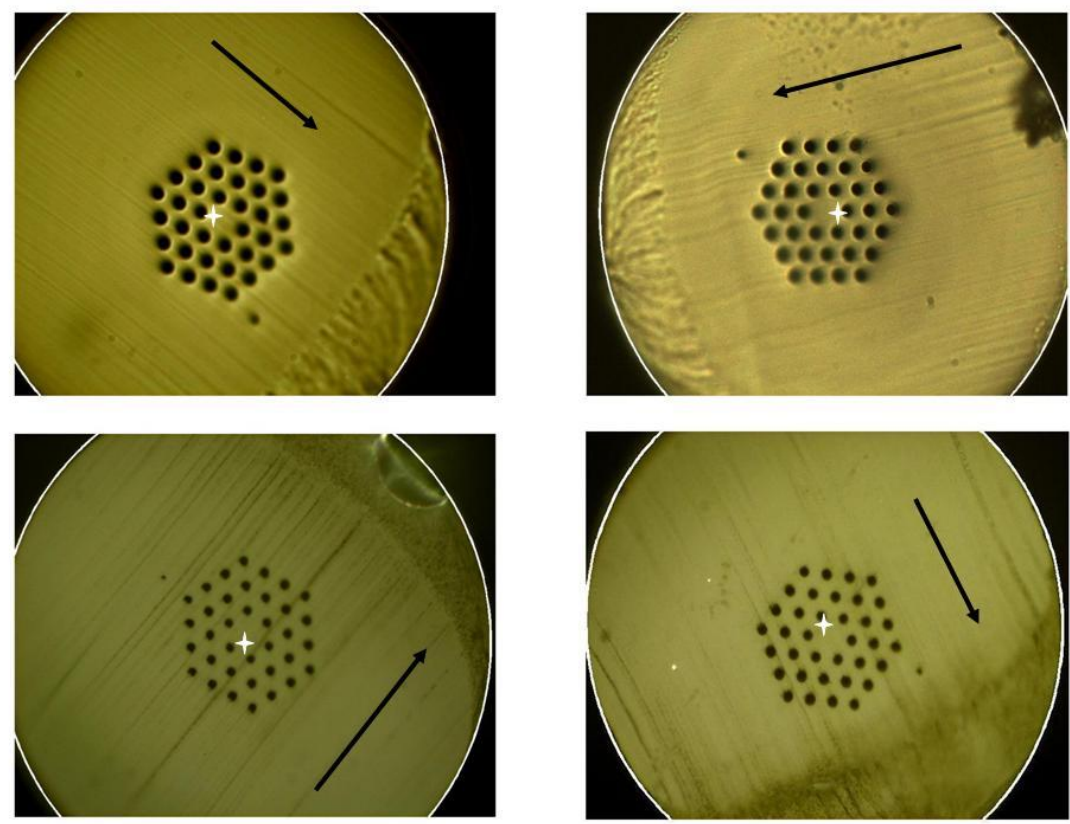

Fig. 5: Four cleaves of the PMMA mPOF made with the same parameters as cleaves A and $\mathrm{B}\left(77.5^{\circ} \mathrm{C}\right.$ for both blade and base), but different orientations. The white ellipse is the program fit to the contour and the cross is the center of the fitted ellipse.

In Fig. 4 we show an example of two good cleaves of the same fiber, but with two different cleaving directions with respect to the hole structure orientation. The cleaving direction is determined by the fine line structure on the bottom left side of the fiber images, where the blade enters, because this is a signature of the blade, as also observed in [34]. Both cleaves have been made with a temperature of $77.5^{\circ} \mathrm{C}$ for both blade and base using a standard $130 \mu \mathrm{m}$ thick wedge-shaped blade (see Fig. 8).

Visually both cleaves seem to be equally good and correspondingly we see that the spread in the pitch ( 84 counts) and the hole diameter (36 counts) is small. From the ellipticity graph it is found that the holes are almost circular after the cleave, with an average ellipticity of only 1.0421 in cleave A and 1.0602 in cleave B. Given that the holes are almost circular in such a good cleave, the major and minor axes will have almost identical lengths and thus the hole direction is expected to fluctuate quite much and be strongly dependent on the cleaving direction with respect to the hole structure. This is also the case, as seen in the graphs for the hole directions.

For cleave $\mathrm{B}$ the hole direction seems to have some correlation along the cleaving direction (zero degrees), with 18 holes out of 36 being in the cleaving direction \pm 18 degrees. However, given the very small average ellipticity of 1.0602 , the tendency is not strong enough to make a definite conclusion.

Given these parameters it appears that we can conclude that the cleave A is slightly better than the cleave $\mathrm{B}$, and that both cleaves are very close to ideally preserving the structure.

However, in order for a cleave to be really good, it also has to result in a small separation between the center of the hole structure (the core) and the center of the fiber, which is marked with a white star in the images in Fig. 4. If the separation is too large, this will lead to significant coupling losses when coupling to, e.g., a commercial silica fiber with a nicely 
centered core. This shift has not been considered in the hitherto published papers on $\mathrm{mPOF}$ cleaving [9,30-34]. From Fig. 4 we find that the shift is $3.5308 \mu \mathrm{m}$ for cleave A and $3.8161 \mu \mathrm{m}$ for cleave B.

For both cleaves A and B the separation is thus a bit more than half a pitch in the opposite direction to the cleaving direction, which means that neither cleave A, nor cleave B, in reality can be characterized as good, even though their average ellipticity was close to 1 .

In Fig. 5 we investigate the dependence of the shift on the cleaving direction by considering cleaves with near optimal temperatures $\left(77.5^{\circ} \mathrm{C}\right.$ for both blade and base) made with 4 different directions.

The shifts are measured to be $2.7272 \mu \mathrm{m}, 3.3341 \mu \mathrm{m}, 2.2306 \mu \mathrm{m}$, and $3.508 \mu \mathrm{m}$, clearly demonstrating that the amount of shift depends on the cleaving direction with respect to the hole structure. We will look more into this shift when considering a "bad cleave" and when optimizing the blade and cleaving parameters in the following.

\section{Cleaving analysis - bad cleave}
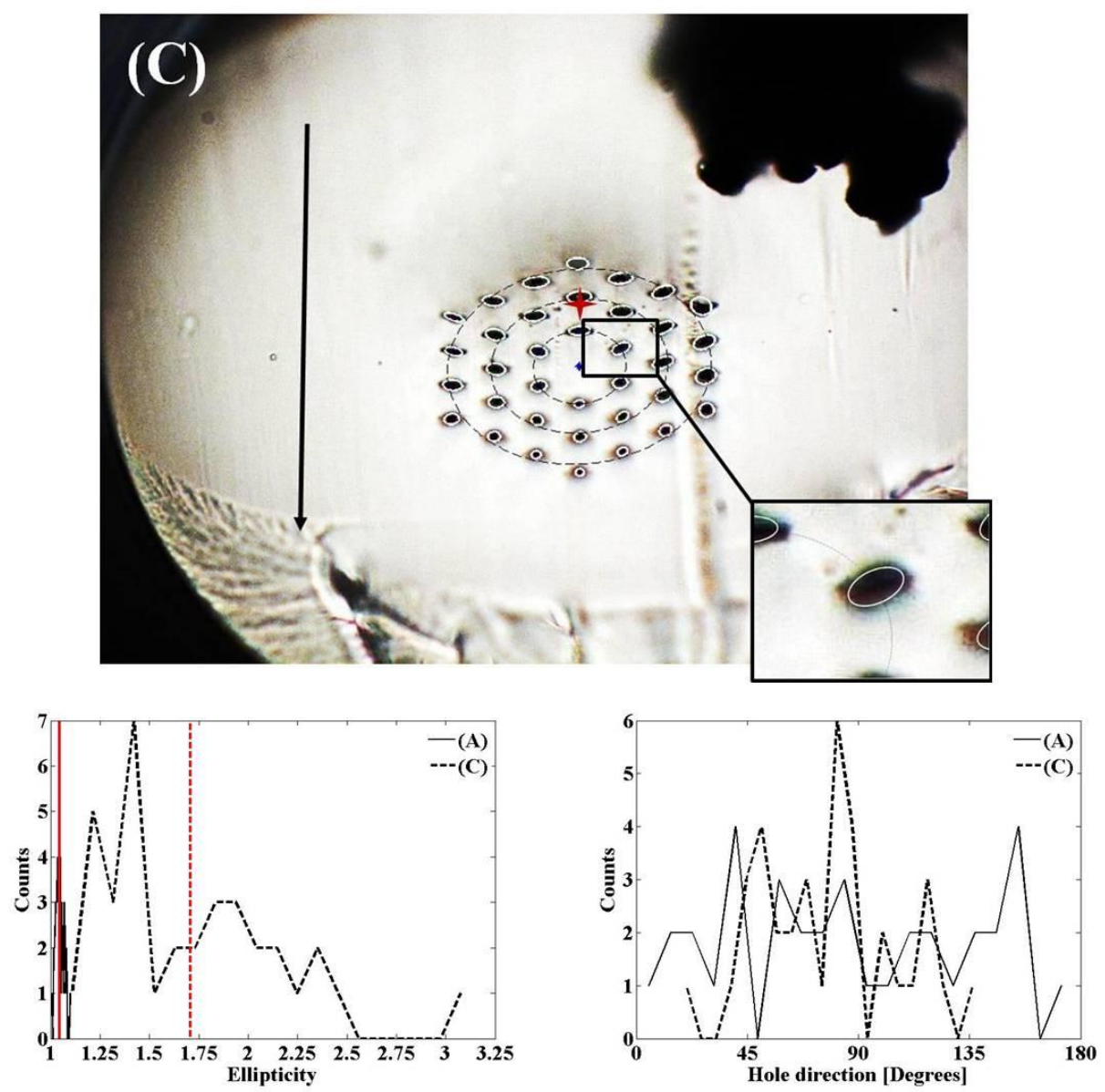

Fig. 6: Cleave of PMMA mPOF with a $60^{\circ} \mathrm{C}$ blade and $70^{\circ} \mathrm{C}$ base temperature (same $130 \mu \mathrm{m}$ wedge-shaped blade as for cleave A and B). Comparison of ellipticity and hole direction between Cleave A (solid) and C (dashed), with curves obtained as in Fig.4. The red star marks the center of the fiber. 


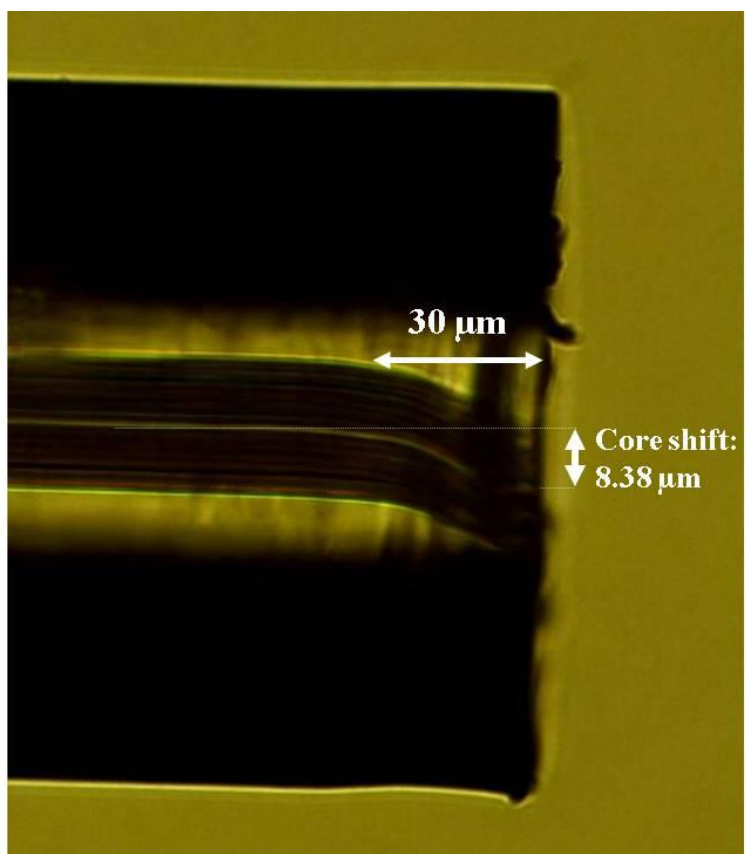

Fig. 7: Microscope image from the side of cleave $\mathrm{C}$ of the PMMA mPOF, showing a core shift of $8.3633 \mu \mathrm{m}$ starting about $30 \mu \mathrm{m}$ inside the fiber.

In Fig. 6 we show the result of a bad cleave $\mathrm{C}$ of the PMMA mPOF, comparing the statistics of the ellipticity and hole direction with that of the good cleave $\mathrm{A}$. Cleave $\mathrm{C}$ has been done with the same parameters as cleave A, except that we have decreased the temperature to $60^{\circ} \mathrm{C}$ for the blade and $70^{\circ} \mathrm{C}$ of the base.

From the image we clearly see how the microstructure has now been squashed by the blade, with the core (red star) being shifted by $8.3633 \mu \mathrm{m}$ or about 2 pitches opposite to the cleaving direction (4 times the shift for cleaves A and B). The average ellipticity has increased to about 1.7086, with even the most circular hole of the cleave $\mathrm{C}$ being more elliptical than any hole of for cleave A. The holes, are now concentrated around $90^{\circ}$ with respect to the cleave direction, which, given the high ellipticity, means that the fiber has been squeezed by the blade. These observations imply a quite big change in the fiber structure itself and leads to the conclusion that the cleaving is "bad".

Let us look a bit closer at the huge shift of the core observed for this bad cleave C. In Fig. 7 we show a miscroscope image taken from the side the PMMA mPOF and cleave C. Here we see that the bending of the microstructured region actually starts about $30 \mu \mathrm{m}$ into the fiber. Due to the two-step sleeving process used in the fiber drawing ( $5 \mathrm{~mm}$ cane sleeved to a $2 \mathrm{~cm}$ secondary preform) the central part inside the white regions in Fig. 7 corresponds to the original cane.

From Fig. 7 we see that it is not the whole cane region, but only the air-hole microstructure that is being squeezed. This should mean that the amount of shift is depending on the cleaving direction with respect to the symmetry of the hole structure, which was also what we observed in Fig. 5. 


\section{Blade thickness and shape}

The best cleaving conditions for PMMA mPOFs have been found to be in the temperature regime where the material has a ductile behavior, just above the transition temperature to being brittle [34]. In this situation the blade is continuously in contact with the fiber material and is separating the fiber sides while passing through it. The fiber gets, consequently, moved apart following the blade shape, which gives the fiber end-facet about the same angle as the blade. The continuous contact and friction between blade and fiber is also responsible for inducing the observed shift of the structure in the cleaving direction. In this section we therefore investigate the influence of blade thickness and shape on reducing the contact and friction.

In Fig. 8 we show cleaves of the same piece of an old PMMA mPOF which had too many holes in the cane-sleeving tube interface and was thus never used. We have fixed the cleaving parameters to $80^{\circ} \mathrm{C}$ for both blade and base, but used blades of different shape and thickness $(130,200,250$, and $300 \mu \mathrm{m})$, given in the respective insets.

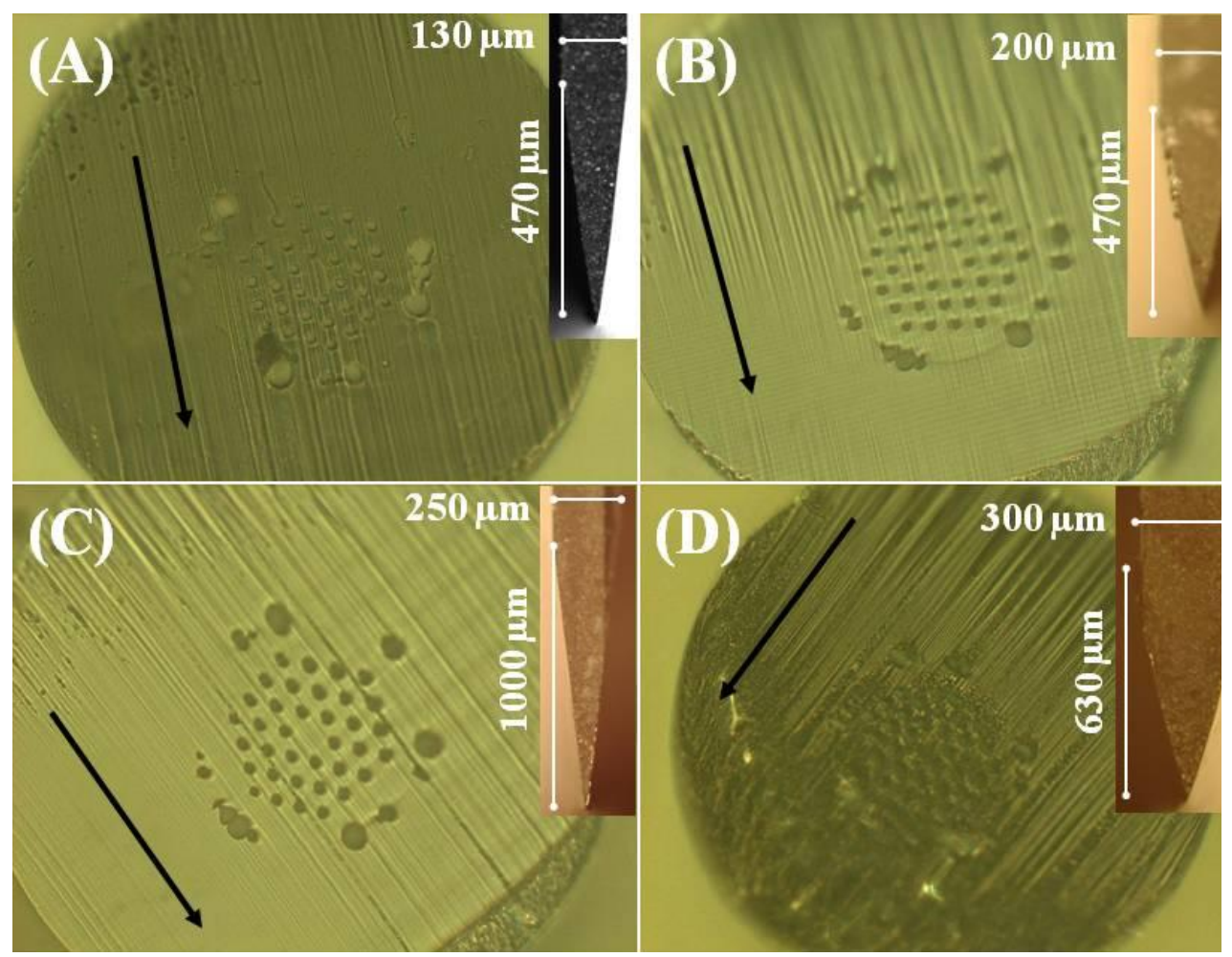

Fig. 8: Microscope images of the "old PMMA mPOF" cleaved with different blades, whose profiles are shown in the insets. The fibers have been cleaved with $80^{\circ} \mathrm{C}$ for both the blade and base.

The first cleave, shown in Fig. 8(A), is with a $130 \mu \mathrm{m}$ thick and $470 \mu \mathrm{m}$ long wedge-shaped blade, which thus has a tip- or wedge-angle of $15.7^{\circ}$. This gave an average ellipticity of 1.28 and a core-shift of $2.42 \mu \mathrm{m}$. Increasing the thickness to $200 \mu \mathrm{m}$ gives an increased wedge-angle of $24.0^{\circ}$. As expected this resulted in a worse cleave with a larger average ellipticity of 1.50 and a larger core-shift of $7.60 \mu \mathrm{m}$, as shown in Fig. 8(B). The $300 \mu \mathrm{m}$ thick and $630 \mu \mathrm{m}$ long blade used for the cleave shown in Fig 8(D) has the largest wedge-angle of $26.8^{\circ}$. Correspondingly, the cleave is very poor. 

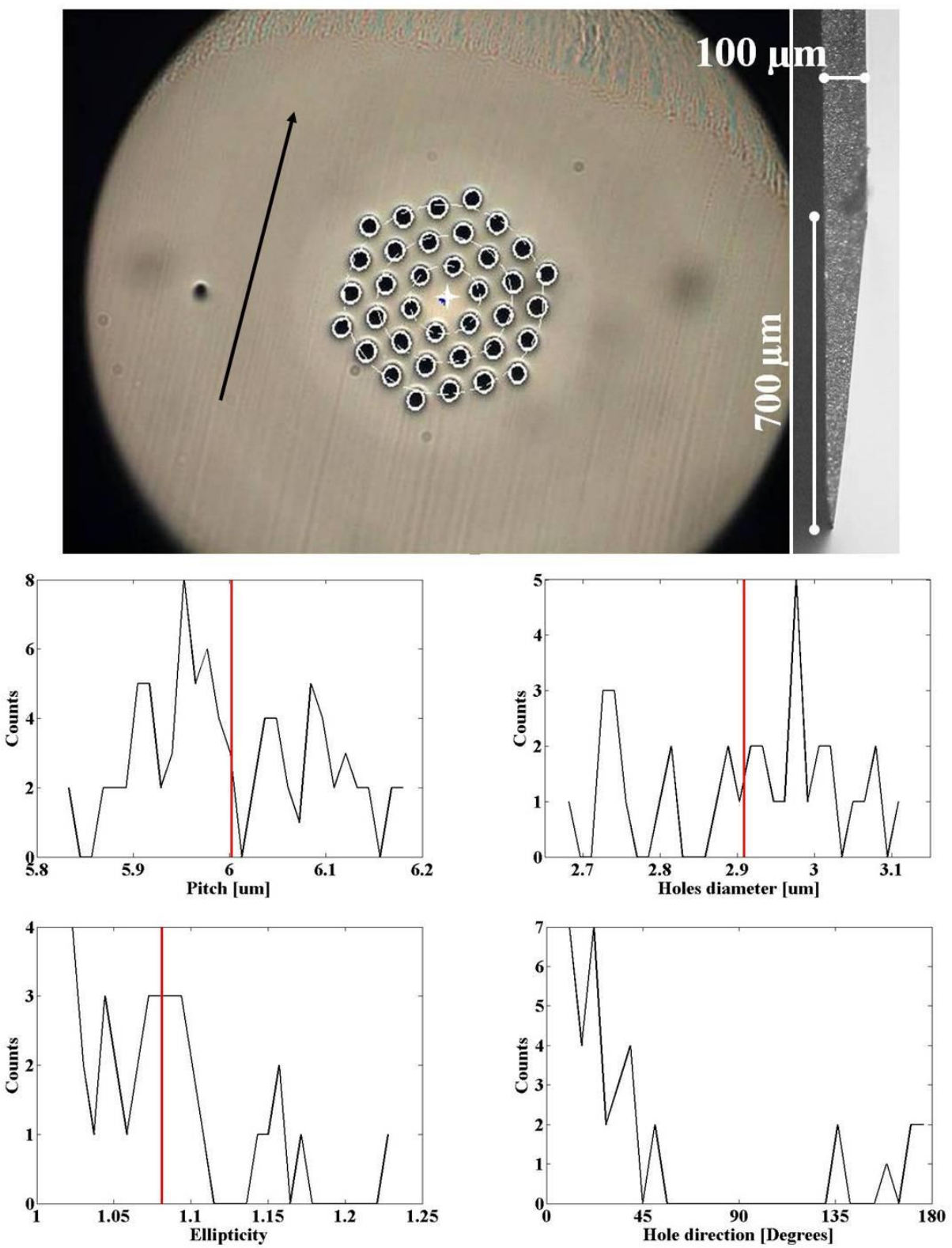

Fig. 9: Microscope image of PMMA mPOF cleaved with a $100 \mu \mathrm{m}$ thick and $700 \mu \mathrm{m}$ long flat-edge blade at the optimum temperature of $77.5^{\circ} \mathrm{C}$ for both blade and base. The statistical graphs below the image are generated as in Fig. 4. Red vertical lines mark the average pitch $6.00 \mu \mathrm{m}$, hole diameter $2.91 \mu \mathrm{m}$, and ellipticity 1.0811 .

The cleave shown in Fig. 8(C) is interesting. It is made with a $250 \mu \mathrm{m}$ thick and $1000 \mu \mathrm{m}$ long blade, whose wedge-angle of $14.3^{\circ}$ is about 1 degree smaller than the wedge angle of the 130 $\mu \mathrm{m}$ blade and should thus result in a slightly better cleave. As expected the average ellipticity of 1.23 is slightly lower than the 1.28 for the $130 \mu \mathrm{m}$ cleave. However, the shift of $4.66 \mu \mathrm{m}$ is much larger than the $2.42 \mu \mathrm{m}$ obtained for the $130 \mu \mathrm{m}$ blade. The reason for this unexpected result might be that the $250 \mu \mathrm{m}$ blade is a non-standard blade with a size of only $0.7 \times 2.5 \mathrm{~cm}=$ $1.7 \mathrm{~cm}^{2}$, which is much smaller than the $2.2 \times 3.8 \mathrm{~cm}=8.4 \mathrm{~cm}^{2}$ of the other three blades and thus much harder to handle in a stable manner. 
In general, the tendency is that when the fiber diameter is much smaller than the length of the wedge-shape at the tip of the blade, then the best cleaving quality is obtained with the smallest wedge-angle.

We therefore acquired a large quantity of the custom-made blade shown in the inset of Fig. 9, which is only $100 \mu \mathrm{m}$ thick and has one flat side. The length of the angled region is $700 \mu \mathrm{m}$, giving it a wedge-angle of only $8.1^{\circ}$. In Fig. 9 we show a cleave of our PMMA mPOF from Fig. 2, made with the new custom-made blade at the optimum temperature of $77.5^{\circ} \mathrm{C}$ for both blade and base (see next section). As expected the cleave is of very high quality, with an average ellipticity of 1.0811 and a core-shift of only $298 \mathrm{~nm}$, corresponding to about $5 \%$ of the pitch.

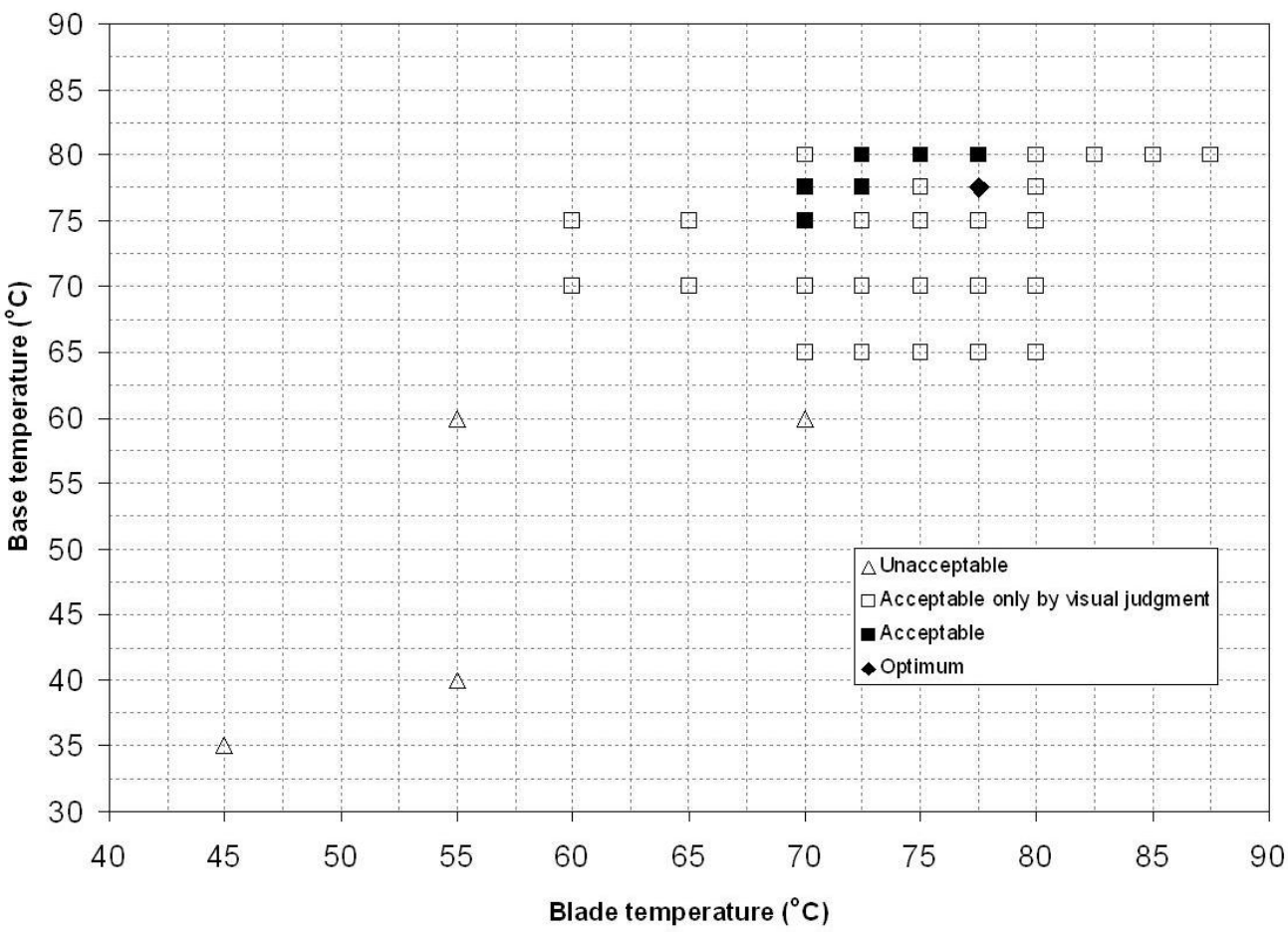

Fig. 10: Cleaving quality versus blade and base temperature for cleaving of the PMMA mPOF with the $100 \mu \mathrm{m}$ flat-edge blade at a speed of $5.6 \mathrm{~mm} / \mathrm{s}$ and an equilibration time of $20 \mathrm{~s}$ Optimum cleaves have an average ellipticity below 1.09 and acceptable cleaves have an average ellipticity between 1.09 and 1.10 .

\section{PMMA mPOF - optimization}

Here we present an optimization of the cleaving temperature of the PMMA mPOF using the fiber end-facet analysis code. We used a cleaving speed of $5.6 \mathrm{~mm} / \mathrm{s}$, an equilibration time of 20 $\mathrm{s}$, and the custom-made flat-edge blade presented in Sec. 6. Only cleaves that have been considered to be acceptable after a quick visual inspection have been processed with the code.

The average hole ellipticity has been used as the quality criterion for judging the cleaves. In particular a threshold of 1.1 in ellipticity has been used to distinguish acceptable from not acceptable cleaves and a level of 1.09 to distinguish between acceptable and optimum cleaves. The results of this investigation are shown in Fig. 10. Acceptable cleaves are generally achieved 
with a blade temperature between 70 and $77.5^{\circ} \mathrm{C}$ and with a base temperature between 75 and $80^{\circ} \mathrm{C}$. The optimum temperature setting is found to be $77.5^{\circ} \mathrm{C}$ for both blade and base, which is the only one satisfying the criterion for optimum cleaving.
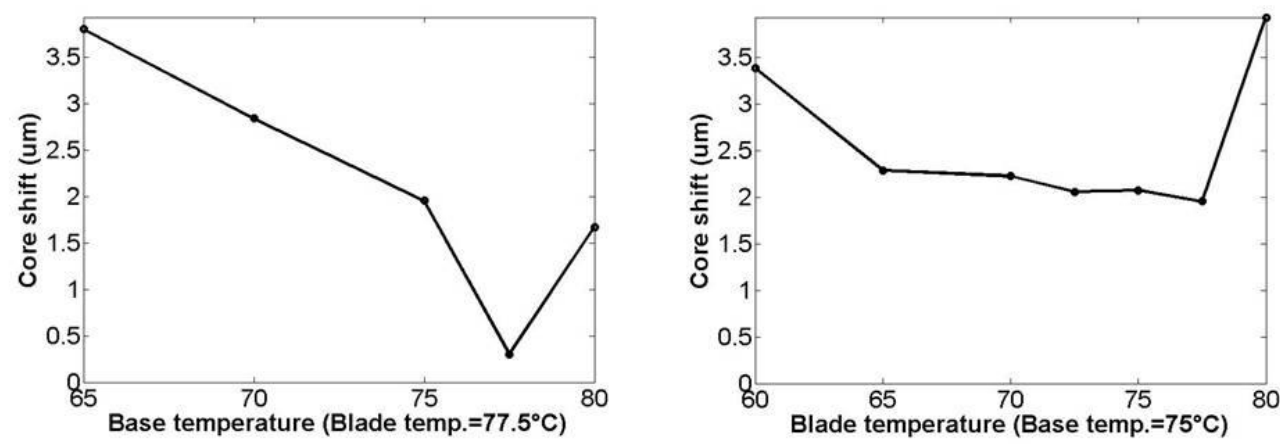

Fig. 11: Core-shift for cleaves in Fig. 10. Left: core-shift vs. base temperature for a fixed blade temperature of $77.5^{\circ} \mathrm{C}$. Right: core-shift vs. blade temperature for a fixed base temperature of $75^{\circ} \mathrm{C}$.

For the optimum temperature setting the cleave and its statistics is shown in Fig. 9, from which we find an average ellipticity of 1.0811. This is actually larger than the average ellipticities of 1.04 and 1.06 observed in Fig. 4 for cleaves A and B with the $130 \mu \mathrm{m}$ blade with a larger wedge angle than our supposedly better flat-edge $100 \mu \mathrm{m}$ blade. However, all these ellipticities are so low that the quality of the microscope focusing becomes a determining factor. A bad focus will, e.g., give rise to shades that will be picked up as ellipticity changes by the program. If we inspect closely cleaves A in Fig. 4 and the optimum cleave in Fig. 9, then cleave A indeed seems to be focused better.

What makes the cleaves with the new flat-edge blade used in the optimization better is their very small core-shift. In Fig. 11 we show how the core-shift depends on the base temperature for a fixed blade temperature of $77.5^{\circ} \mathrm{C}$. The graph shows a clear minimum at the optimum cleaving settings of $77.5^{\circ} \mathrm{C}$ for both base and blade, where the core-shift is only $298 \mathrm{~nm}$ or $5 \%$ of the average pitch of $6.0 \mu \mathrm{m}$. The existence of a minimum core-shift is also apparent when the temperature is slightly off the optimum, as seen in Fig. 11 for a fixed base temperature of $75^{\circ} \mathrm{C}$. The optimum temperatures of the minimum correspond nicely to the transition from brittle to ductile behavior of PMMA observed in the work of Law et al. [30,34].

\section{TOPAS $®$ mPOF - optimization}

We now look at the optimum cleaving temperatures of the TOPAS ${ }^{2}$ mPOF using the same blade, cleaving speed, and equilibration time as for the PMMA mPOF. The properties of TOPAS ${ }^{\circledR}$ grade 8007 are much different than PMMA. For example, the glass transition temperature is only $\mathrm{T}_{\mathrm{g}}=80^{\circ} \mathrm{C}$ (see www.ticona.com). It is thus to be expected, that the optimum cleaving temperatures are lower than those for the PMMA mPOF.

The cleaving results are shown in Fig. 12, from which we see that the optimum temperature is $40^{\circ} \mathrm{C}$ for both the blade and the base. A range of temperatures between 25 and $40^{\circ} \mathrm{C}$, for both the blade and the base, can be used to obtain acceptable cleaves. For this analysis the ellipticity value, below which a cleave has been considered acceptable, is 1.21 , while optimum cleaves have an ellipticity below 1.19 . At $40^{\circ} \mathrm{C}$, for both the blade and the base the average ellipticity is the lowest at 1.16 . Here the core-shift is $4.288 \mu \mathrm{m}$, which is $51 \%$ of the average pitch $8.4 \mu \mathrm{m}$ (see Fig. 2). 


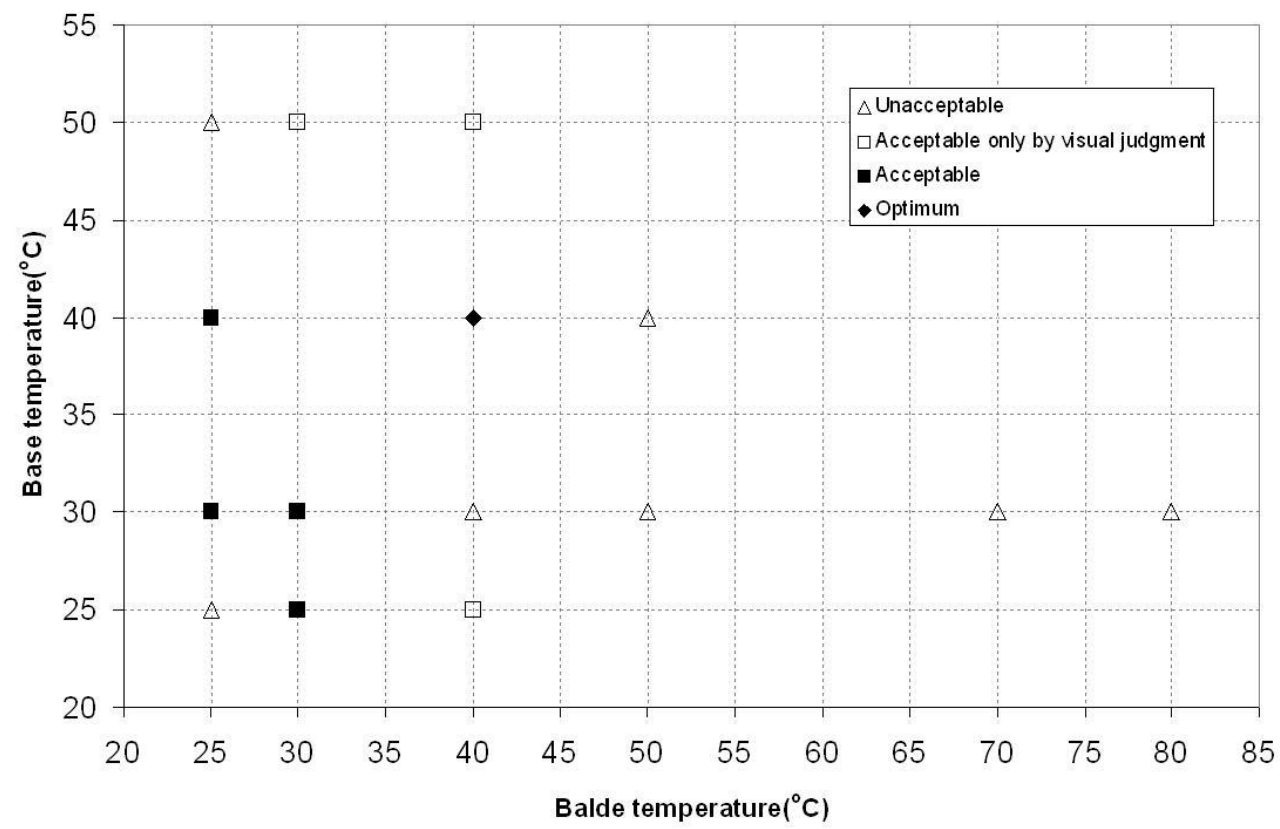

Fig. 12: Cleaving quality versus blade and base temperature for cleaving of the TOPAS® $\mathrm{mPOF}$ with the $100 \mu \mathrm{m}$ flat-edge blade at a speed of $5.6 \mathrm{~mm} / \mathrm{s}$ and an equilibration time of $20 \mathrm{~s}$ Optimum cleaves have an average ellipticity below 1.19 and acceptable cleaves have an average ellipticity between 1.19 and 1.21 .

One more observation about TOPAS $®$ grade 8007 can be made: being so soft it is really easy to create scratches on the end-facet of the fiber, which makes it more sensitive to blade imperfections and damages. More over this is probably the reason for which the hole ellipticity is larger in TOPAS ${ }^{\circledR}$ fibers than in PMMA fibers. Other grades of TOPAS ${ }^{\circledR}$ have higher glass transition temperatures and are thus expected to have higher optimum cleaving temperatures.

In general the same cleaving quality variation applies to TOPAS ${ }^{\circledR}$ grade 8007 , as PMMA, which could suggest that a brittle to ductile phase transition also exists for the TOPAS®.

The quality of the cleaves of TOPAS ${ }^{\circledR}$ fibers could be improved by modifying the instrument (for example by using a motor with a different step size). In fact, until now this kind of cleaver has only been implemented for PMMA fibers and then used for TOPAS® fibers.

\section{Conclusion}

In this article we have studied cleaving of $125 \mu \mathrm{m}$ thick industry grade PMMA and $280 \mu \mathrm{m}$ thick TOPAS ${ }^{\circledR}$ grade $8007 \mathrm{mPOFs}$ with a standard hexagonal hole structure. In the study we have used a statistical numerical tool, which reads in an image of the end-facet of the cleaved fiber, and provides a statistical analysis of the hole structure and, as a novel parameter, the coreshift.

The numerical code and the variation of the core-shift, has allowed us to identify a $100 \mu \mathrm{m}$ wide and $700 \mu \mathrm{m}$ long flat-edge blade as the optimum of the blades we considered (conventional razor blades are purely wedge-shaped). With a wedge-angle of only $8.1^{\circ}$ at the tip, this blade provided very small core-shifts of only $298 \mathrm{~nm}$ or $5 \%$ of the pitch for the PMMA 
$\mathrm{mPOF}$ and $4.288 \mu \mathrm{m}$ or $51 \%$ of the pitch for the TOPAS ${ }^{\circ} \mathrm{mPOF}$, at their respective optimum cleaving temperatures.

The optimum cleving temperature were identified using the code and considering the average hole ellipticity as the quality parameter. With the flat-edge blade the optimum temperature was $77.5^{\circ} \mathrm{C}$ for the PMMA mPOF and $40^{\circ} \mathrm{C}$ for the TOPAS ${ }^{\circledR} \mathrm{mPOF}$, for both fiber and blade. The settings gave average ellipticities of 1.08 and 1.16 for the PMMA and TOPAS® mPOFs, respectively.

While the temperatures of $77.5^{\circ} \mathrm{C}$ for acceptable cleaves for the PMMA mPOF are within the regimes found in the original work by Law et al. on graded-index mPOFs of optical grade PMMA [34], we have now found the optimum temperatures for this type of industry-grade PMMA mPOF and quantified its structural statistics. In particular, it was found that the coreshift had a minimum at the optimum setting, clearly relating to the known brittle-to-ductile phase transition of PMMA at these temperatures [34].

The lower cleaving temperature of only $40^{\circ}$ of the new type of TOPAS ${ }^{\circ}$ mPOF grade 8007 reflects the low glass transition temperature of $80^{\circ}$ of this particular grade, which is also the reason why the average hole ellipticity was higher than for PMMA. The result emphasizes the fact the different mPOFs of different polymers require different cleaving temperature.

\section{Acknowledgments}

We would like to acknowledge support from the Danish National Advanced Technology Foundation. 